\title{
The Great Semblance Is Invisible—Lao tzu and Chuang tzu’s Cognitive Aesthetics
}

\author{
ZHANG Xian-jun \\ Southwest Jiaotong University, Chengdu, China
}

\begin{abstract}
In the paper I will research Lao tzu and Chuang tzu's cognitive aesthetics based on the generalized cognizance. Lao tzu and Chuang tzu are the representative figures of Taoism in pre-Qin period, they fully affirm the natural and human nature, naysay affirm human social, cultural and moral, cancel the traditional music, naysay affirm material, they pursue art which is eligibility natural and completely abandon the man-made things, esthetical state according with Tao. They think the great voice is no sound, the great semblance is invisible, the no sound voice and invisible semblance are insight native beauty which are associated with a specific aesthetic feeling but surpass the limited aesthetic feeling, all is the highest state of art and beauty, reach this level, in fact, has entered the Tao. In order to reach this state, they asked people to cleanse away inner desire and external disturbance, keep simplicity, abandon knowledge and wisdom, keep heart bright and clean, forget everything in order to contact the natural law with the nature, the nature's mystery runs automatically, the sounds of nature sound itself. About the invisible semblance aesthetic, they put forward the concepts such as gain its meaning but forget the word, illocutionary force.
\end{abstract}

Keywords: cognitive poetics, Lao tzu, Chuang tzu, Tao

\section{Introduction}

Cognition is one of the important fields of psychological research, refers to the process of human obtaining the knowledge or learning, it is the action and ability by which the brain understands the things and acquires knowledge corresponding to the mental activities such as emotion, motivation, vilition. Thinking is the core of cognition, the highest comprehensive stage in the process of information processing, formed on the basis of the perception, presentation and memory, affecting the process of perception, representation, and memory in return. As literature research methodology, cognitive poetics is a kind of Western poetics theory after the rise of cognitive science, mostly using cognitive psychology, cognitive science and cognitive stylistics to explain literature. Different from the West, as early as Chunqiu and Warring States Period, China presented its unique cognitive esthetics thoughts-Taoism's cognitive esthetic theory.

Chunqiu and Warring States Period is the axial age of China. During this period, the independent warlords rose in swarms, attacks mutually in politics and military, meanwhile in the field of ideology the pre-Qin thinkers enlivened, debated mutually, elaborated their respective ideas and thoughts that formed ideological prosperity - a hundred schools of thoughts contending. As the pre-Qin period Taoism's representative personage, Lao tzu and 
Chuang tzu interpreted their own cognitive aesthetic idea in their works proceeding from the concept of Tao, established the Chinese early time cognitive poetics system.

\section{The Basis of Lao tzu and Chuang tzu's Cognitive Aesthetics-Tao Whose Existence Spring From It as Non-existent}

Taoism is an ideological school in ancient China which rose in Chunqiu and Warring States Period, besides the Confucianist, it is the more significant school in all classes of authors. The founder of Taoism is Lao tzu (It is said that Lao tzu's surname is Li Er, secondary personal name is Dan), his philosophy and aesthetic ideas reflected in his book Laozi (also known as The Tao Teh King). Lao tze applied Tao to explain the evolution of the inventory in the universe, Tao is the objective law of nature, and also has the eternal significance that "standing alone, and undergoing no change, reaching everywhere and in no danger of being exhausted” (CHEN, 2003, p. 169). He thinks in the world things are the unity of existence and non-existence, "existence spring from the non-existence", and "non-existence" as the foundation, "All things under heaven spring from it as existing and named; that existence spring from it as non-existent and not named” (CHEN, 2003, p. 226). The representative figure of the Taoism in the Warring States Period is Chuang Zhou, he wrote the book Chuangzi. Chuang tzu inherited and carried forward the thoughts of Lao tzu, he also boiled the origin of the inventory in the universe down to the Tao. He fully affirmed the innate quality of the nature and human beings, denied the artificial society, culture and morals, cancelled the traditional ritual music, didn't strive for plenty of material life, did not drive by material system, sought for the freedom realm which is suitable for nature. Chuang tzu overcame mountains and rivers to research the world, integrated the meaning of the universe into the romantic charm and mien of people, researched the realm that the excellent people who did not concern himself, the immortal who did not concern his material gain, the saint who did not concern his reputation. In the history of Chinese literary theory, beauty-appreciation literary thoughts came into being under the influence of the thoughts of Taoism that advocates natural and pursuit of natural verve.

The concept of Tao first seen in The Book of Changes, It says: “Alternating between Yin and Yang is called Tao" (WANG, 1980, p. 541). It means that the intercourse of Yin and Yang is the starting point of the universe changes. Or, Yin and Yang are parents of the temporal.

The core of Chinese classical Taoist philosophy is the Tao. Taoist summed up the nature of the universe in Tao, regarded the Tao as the original chaos. Although said that all things under heaven spring from Tao, it may be regarded as the mother of all things, Lao tze did not give a clear definition to Tao, just as his words "the Tao that can be trodden is not the enduring and unchanging Tao" (CHEN, 2003, p. 73). Tao is a thing which is uncertainty, deep and remote, elusive, "I do not know its name, and I give it the designation of the Tao (the Way or Course). Making an effort (further) to give it a name I call it The Great” (CHEN, 2003, p. 169). Tao reflects empty, but can be used endlessly, it is the source of all things, seems profound, deep and serene. Therefore, in his view, the Tao is the existence of the reality,

Who can of Tao the nature tell? Our sight it flies, our touch as well. Eluding sight, eluding touch, The form of things all in it crouch; Eluding touch, eluding sight, There are their semblances, all right. Profound it is, dark and obscure; Things' essences all there endure. Those essences the truth enfold of what, when seen, shall then be told. (CHEN, 2003, p. 156) 
Its name will never be abolished back to ancient times from nowadays, only according to it can we observe the initial of all things. So Tao contains at least the tangible things which include the semblances of things, the things and things' essences. These tangible things have their regularities, distinctiveness and limits, the differences of things come from Tao. Lao tzu thought that Tao is the unity of existence and non-existence meanwhile affirming its objectivity:

So it is that existence and non-existence give birth the one to (the idea of) the other; that difficulty and ease produce the one (the idea of) the other; that length and shortness fashion out the one the figure of the other; that (the ideas of) height and lowness arise from the contrast of the one with the other; that the musical notes and tones become harmonious through the relation of one with another; and that being before and behind give the idea of one following another. (CHEN, 2003, p. 80)

The so-called "non-existence", that is, Tao is indescribable, non-polar, we meet it and do not see its Front; we follow it, and do not see its Back, that is no stipulation, limitless. Therefore, Tao is no concrete image, cannot be grasped only by feeling. Both "existence" and "non-existence" are Tao, Tao has the dual attributes of "existence" and "non-existence". That is to say, the Tao cannot only be a tangible physical state, but aslo an invisible ideology state (psychology concept image). Lao tzu thought that although there is a dialectical relationship between nothing and thing, virtual and real, "existence and non-existence give birth the one to the other", existence springs from non-existence, regards non-existence as its root, while the people can experience and taste the realm of "non-existence" from "existence".

Although Chuang tzu's Tao is more mysterious than the idea of Lao tzu, he deeply understood the freedom and its own deed of the universe spirit, so let it be, open unlimited facing to the chaos. Chuang tzu thought that the body is the shelter of the short things, but the spirit is the eternal conversion, the opening of Great Tao is not only the infinity of territory space but also the infinity of all people and all things, it is a kind of extension of the limited survival, so as to transcend the helpless of time and space, only depending on the endless continuation of the spirit, the unification of Great Tao can we be able to transcend the limitations of individual life and survival, to pass through the fear and sadness of the life to search out the natural and spiritual homeland. Just because of the unlimited open, his Tao cannot be described as well, it is quite confused and stupefied, intangible and traceless, imageless and nameless, self-sourced and self-rooted. Also because of this, his Tao has the ethereal effects of aesthetic meaning. When he inspected external world relying on the ethereal state of aesthetic judge, he revealed the eternal meaning of existence — the great beauty and the great joy.

\section{Lao tzu and Chuang tzu's Cognitive Principle-The Law of the Tao Is Its Being What It Is}

Researching on the origin of aesthetic consciousness, different from the visual dominance in traditional Western culture, the initial notion in the Chinese traditional culture is likely to be "The beauty of the sense of taste", then expanded gradually to the audiovisual beauty. The perception of this order was recorded in The Twenty-Fifth Year of Duke Zhao in Zuo's Commentary on Spring and Autumn Annals: "The pneuma sends out five flavors of acid, salty, pungent, sweet and bitter, turns into five colors of cyan, yellow, red, white and bright, appears five music of gong, shang, jue, zhi and yu” (CHEN, 2006, p. 2639). Chinese aesthetic-appreciation activity is a comprehensive feeling with taste, hearing, vision, touch sensation, kinesthetic, words, Chuang tzu's "Let your senses communicate within and rid yourself of the machinations of the mind" (CHEN, 2007, pp. 
139-140) is a kind of comprehensive aesthetic feelings. In the traditional Chinese aesthetic cognition, Taoist school pays more attention to this kind of transition from outer to inner, let us read the dialogue spoken by Yen Hui and his teacher Confucius in Zhuangzi (In the world):

"I have nothing further to propose,” said Yen Hui. "I venture to ask you for a method.”

"Fasting," said Confucius. "I shall explain it for you. If you do things with your mind, do you think it will be easy? Bright heaven will not approve one who thinks it will be easy.”

"My family is poor,” said Yen Hui, “and it’s been several months since I've drunk wine or tasted meat. May this be considered fasting?”

"This is fasting suitable for sacrifices, but it is not fasting of the mind."

"I venture to ask what 'fasting of the mind' is," said Hui.

"Maintaining the unity of your will,” said Confucius, "listen not with your ears but with your mind. Listen not with your mind but with your primal breath. The ears are limited to listening, the mind is limited to tallying. The primal breath, however, awaits things emptily. It is only through the way that one can gather emptiness, and emptiness is the fasting of the mind." (CHEN, 2007, p. 139)

The philosophical basis of Taoist poetics thoughts is Tao. Tao refers to a kind of absolute idea that exists beyond time and space, it can dominate and control the psychic will of the main body, contains strong personalized power and factors. Although Tao has the supreme status, it is unknowable and unconfirmed, and the "fasting", "sit and forget" are two ways that the subject of literary and artistic creation to carry out and fulfill the Tao. In the process that the subject of literary and artistic creation perceives things, the empirical glance by ear, heart, pneuma, emptiness is Fasting, it is the best state of mind to experience the Tao, a clear and bright psychological state, at this moment you need to use neither audio and visual senses nor rational thinking, fully comprehend by intuition of life instinct. In the process that perceives things, the subject of literary and artistic creation gets rid of physical and mental desire, reaches the psychological state in which one forgets shape and feeling, oneself and things, this state is Sit and Forget. In terms of the name "fasting", "Sit and Forget" are two states, but they are the one in actual fact, its essential requires the subject of literary and artistic creation through the intuitive experience to understand and experience, grasp the essence of things, so as to surpass the reality, obtain spiritual freedom realm of Tao. That is to say, the aesthetic attitude of the subject of literary and artistic creation must reach the mental state in which one forgets himself and other things, keeps the mind clear and bright.

Thus, how does the subject of literary and artistic creation achieve this state? According to Lao tzu, they must know "the law of the Tao is its being what it is", in accordance with the innate quality of nature, live and perceive naturally and lightheartedly. First, cleanse away the inner desire and external disturbance (Xuanjian) in terms of thinking. "When one gives undivided attention to the vital breath, and brings it to the utmost degree of pliancy, he can become a tender babe. When he has cleansed away the most mysterious sights of his imagination, he can become without a flaw" (CHEN, 2003, p. 108). "Cleanse away" refers to wash the inner desires, eliminate external disturbance; "Xuanjian (mysterious sights)" evolve to "Xuanlan (the vision of the mystery)" at a later time, means to view the Tao of metaphysics from physical thing in the world, the so-called "essential intuition" today. Because of viewing from concret to metaphysics, so called "Xuan (mysterious)". But in fact the metaphysics is unable to view, so it is actually a kind of comprehension. The original intention of Lao tzu is to view the Tao, only eliminating disturbance of the distracting thoughts can we go deep into essence to meet Tao. 
This viewpoint communicates with aesthetic contemplating, reveals the regularity that aesthetic contemplating and artistic creation must be on the premise of clear state of mind. All the discourses "stands in the center and observes in the darkness", "cleanse your mind, purify your spirit" in A Poetic Exposition on Literature (written by Lu Chi) and Wen xin diao long (written by Liu Xie) were developed from here.

Next, keep simplicity. In chapter 19 of his work, Lao tzu said:

If we could renounce our sageness and discard our wisdom, it would be better for the people a hundredfold. If we could renounce our benevolence and discard our righteousness, the people would again become filial and kindly. If we could renounce our artful contrivances and discard our scheming for gain, there would be no thieves nor robbers. Those three methods of government thought olden ways in elegance did fail and made these names their want of worth to veil; but simple views, and courses plain and true would selfish ends and many lusts eschew. (CHEN, 2003, p. 147)

Lao tze advocated non-action ruling in politics, praised natural on philosophy and aesthetics, thus he advocated maintaining natural simplicity.

He who devotes himself to learning seeks from day to day to increase his knowledge; he who devotes himself to the Tao seeks from day to day to diminish his doing. He diminishes it and again diminishes it, till he arrives at doing nothing on purpose. Having arrived at this point of non-action, there is nothing which he does not do. (CHEN, 2003, p. 250)

Chuang tzu also proposed that "subscribes to nonaction an dreturns to the simplicity of the unhewn log" (CHEN, 2007, p. 373), (Heaven and Earth) "after all the carving and chiseling, return to the simplicity of the unhewn log” (CHEN, 2007, p. 588) (The Mountain Tree). This is the development of the thoughts of Lao tzu's "simple views and courses is plain". "Nature" and "Simplicity" are the two kinds of aesthetic styles put forward by Chuang tzu about the object of literary that associated with each other.

The Tao in Chuang tzu's philosophy is nature, nature is unable to change, keep the innate quality of nature so as to get esthetical effect. "Simplicity" is consistent with the concept of "nature", mainly refers to a style which is clear, pure and determined by nature. Chuang tzu expounded his ideas on this style mainly from four aspects: Heaven and earth have great beauty but do not speak; follow along with the nature of things; after all the carving and chiseling, return to the simplicity of the unhewn log; simple as an uncarved block, no one under heaven can contest with them for excellence. Chuang tzu thought, literary and artistic creation should comply with and abide by the innate quality of nature, seek the highest state beauty of the nature; the means of literary and artistic creation is to achieve the effect of the simplicity, the beauty of simplicity is more beautiful than any other type of beauty. Chuang tzu, in fact, regarded the "nature" and "simplicity" as the highest aesthetic style of the object in literary and artistic creation.

Chuang tzu thought, things are beautiful because they are natural, any artificial art is damage to the natural beauty. In On the Equality of Things, he compares the pipes of heaven, the pipes of earth and the pipes of man to illustrate the beauty of nature: "The pipes of earth are none other than all of the hollows. The pipes of man are bamboo tubes arrayed in series", "As for the pipes of heaven, the myriad sounds produced by the blowing of the wind are different, yet all it does is elicit the natural propensities of the hollows themselves. What need is there for something else to stimulate them!” (Chen, 2007, p. 139). The pipes of man is the music played with music orchestra by people, is artificial things, belongs to lower down sound; the pipes of earth is the sound that the wind blow big and small orifice, its coming into being by virtue of the size of the wind and the different shapes of the orifice, also is not the most beautiful; only the pipes of heaven is natural voice that the orifices resound 
themselves, not depend on any external forces. Because the pipes of heaven synthesizes the pipes of earth and the pipes of man, it must be provided with two conditions, the one is out of itself, and the second is due to the nature. If we get the two conditions together, the pipes of heaven is our own sound of nature. Chuang tzu opposed to modify, advocated the sounds of nature sound itself.

The premise of keeping simplicity is to abandon knowledge and wisdom. Lao tze thought, human activities should be limited to the scope "necessary and follow along with the nature of things", should follow the morality to seek the Tao. People following the morality is that they act according to the innate quality of things, because people's desire is too much in real life , in order to meet the desire, pursue pleasure, people lost the intrinsic morality, they should have few desires. Knowledge itself is the object of desire, it can also inspire more desire of people, the more knowledge they have, the less satisfied and inactive they are, that is why people need to abandon knowledge and wisdom, keep the original ignorant state. Here the "discard wisdom" shows the active excluding, that is to say, people should keep their simple natural character. Comparing with Lao tzu, Chuang tzu had the obvious progressing, he emphasized that people should respect the inherent law existed objectively in the things rather than going against it discretionarily according to their subjective will. In Chuang tzu's view, people must abandon the knowledge so as to follow the Tao. In Essentials for Nurturing Life, Chuang tzu said: "Our lives are limited, but knowledge is limitless. To pursue the limitless with the limited is dangerous. Such being the case, if one still goes after knowledge, one's life will definitely be in danger" (CHEN, 2007, p. 113). In such cases, if the people are still bound to pursue knowledge, it is the loss of the Tao to make themselves fall into endless troubles in the joys and sorrows. Chuang tzu put it this way is not advocating "ignorance" but stressing "wisdom of unwisdom", requiring people after "wisdom" to achieve the unwisdom stage, reaching the state of mind in accord with great Tao on the basis of cognizing regularities of all things on earth. So he went on: "Follow the central artery as conduit, you can preserve your body, maintain your life, nourish your inmost viscera, and complete your allotted years” (CHEN, 2007, p. 113).

"The law of the Tao is its being what it is" is a state of doing everything at the point of non-action and returning artless innate quality. Therefore, at the beginning of the artistic creation, Taoism emphasizes the artist must be in emptiness and stillness state of mind. Emptiness and stillness is the precondition of artistic conception, it is a concentrated state of mind not be disturbed by any subjective or objective factors. After artists enter into the emptiness and stillness state, they can get rid of all the fetters of secular utilitarian, concentrate on in-depth artistic conception. "Emptiness and stillness" first came forward in Laozi "The state of vacancy should be brought to the utmost degree, and that of stillness guarded with unwearying vigour” (CHEN, 2003, p. 134). Chuang tzu greatly developed Lao tzu's theory on "Emptiness and stillness", he thought that "Emptiness and stillness" is the required state of mind when we come into the state of Tao, is the basis of the understanding to supreme Tao, due to the fact that "Emptiness and stillness" can make the person "purge knowledge", break all the limitations of artificial knowledge so as to reach the perfectly clear state on understanding.

In Preserving and Accepting, Yellow Emperor asked Master Guangcheng what is the best Tao of health maintenance. Master Guangcheng answered that Tao is the objective law which is invisible and impalpable, thus it is cavernously dark, profoundly silent. However, must you hold the objective laws in gloom state can you stay healthy and longevity. Because the objective law is invisible and impalpable, people need to be "neither sight nor hearing”. Neither sight nor hearing really let you turn a blind eye and a deaf ear to the reality, but don't look and 
hear blindly. In the face of rapidly changing, multicoloured, affect the physical and mental health things, don't persistent in any case, look like unsighted, hear like unheard, only operating according to Tao that is to say the objective laws can everything embrace the spirit in stillness.

\section{Chuang tzu said in The Way of Heaven:}

He who understands heaven, who is conversant with the sages, and who comprehends the virtue of emperors and kings throughout the six directions of the universe and the four regions, acts spontaneously but is always obliviously still. The stillness of the sage is not because stillness is said to be good and therefore he is still. It is because the myriad things are unable to disturb his mind that he is still. When water is still, it clearly reflects whiskers and brows. It is so accurate that the great craftsman takes his standard from it. If still water has such clarity, how much more so pure spirit! The stillness of the mind of the sage is the mirror of heaven and earth, the looking glass of the myriad things.

Emptiness, stillness, placidity, mildness, quietude, indifference, nonaction - these are the root of heaven and earth, the substance of the Way and virtue. Therefore, emperors, kings, and sages rest in them. Resting, they are empty; empty, they are full; full, they are prepared; empty, they are still; still, they begin to move; moving, they attain. Still, they are nonactive; nonactive, they entrust the responsibility for affairs to others. Nonactive, they are content; content, anxiety, and trouble cannot discomfit them; so their longevity will be great.

Emptiness, stillness, placidity, mildness, quietude, indifference, nonaction - these are the root of the myriad things. Understanding this as the south-facing ruler, Yao was lord; understanding this as the north-facing minister, Shun was his subject. Occupying a superior position with this understanding is the virtue of emperors, kings, and the son of heaven; occupying an inferior position with this understanding is the way of dark sages and plain kings. Those who withdraw into retirement with this understanding and wander at leisure will win the admiration of recluses from the rivers, lakes, mountains, and forests. Those who come forward into active life and succor the world with this understanding will achieve great accomplishments and brilliant fame by uniting all under heaven. Still, they are sages; moving, they are kings. Nonactive, they are respected; simple as an uncarved block, no one under heaven can contest with them for excellence. (CHEN, 2007, p. 393)

The purpose of Emptiness and stillness is to make people's heart like the mirror of the heaven and the earth and, mirror of everything in the world, only abandoned all specific, partial, subjective "seeing", "smelling" and "knowing” can the people enter into the perfectly clear state, obtain the uppermost, all-sided and real objective understanding to the things, observe aesthetic freely, have the most exuberant artistic creativity, create works in full accord with nature.

What mentions in the same breath with "Emptiness and stillness" is "Sit and Forget". In The Great Ancestral Teacher, Chuang tzu proposed: "dim my intelligence, depart from my form, leave knowledge behind, and become identical with the Transformational Thoroughfare. This is what I mean by 'sit and forget'” (CHEN, 2007, p. 240). What the Chuang tzu says "sit and forget" is exactly "emptiness and stillness". That is letting people forget everything exists as well as their own existence, abandon all knowledge, reach the state of vacancy should be brought to the utmost degree and that of stillness guarded with unwearying vigour, integrate with the Tao. In the Taoist view, artist's mind should settle as still water when he carries through artistic creation and artistic view, at this time they can reach the mental state that enjoy beautiful scenes in empty and clear mind, agree with nature, accommodate everything in the mind, can return to nature in the aspect of spirit, its expression is fully liberation of his own nature of mind, making his mood to get quiet, peaceful, lonely and inactivity, make his soul suffuse with the cognitive object, as if integrating with the universe, sublimate to the state of selflessness.

As to the specific manifestation of the "sit and forget", Chuang tzu proposed the idea of "materialization", he advocated that in the process of realizing the Tao of objective things, at the psychic emptiness and stillness 
state, the people as main body should reach also can reach an uppermost state in which things and ego are isomorphic, they are all-in-one with the Tao, that is to say, the boundaries between the object and the subject of the cognition are thoroughly obliterated. The materialization theory of Chuang tzu is closely linked with his emptiness and stillness. Chuang tzu thought "emptiness and stillness" is the way and method to understand Tao, is a required state of mind when people want to enter into the state of Tao. For the creation subjects, must have the emptiness and stillness state of mind, which is the key whether they can create natural art. For the relationship between subject and object in creation, must reach the materialization state. What is the "materialization"? In Chuang tzu's view, after entering into emptiness and stillness state, abandoning all disturbance and the psychological burden, people will forget everything even themselves, no longer being tied and restricted to own sense organs, so as to get the perfectly clear cognition. Such as the wheelwright was hewing a wheel in The Way of Heaven and the draftsman who was found half-naked, with his shirt off, sitting with his legs splayed out in Sir Tian Zifang, Chuang tzu put forward his viewpoint under the guise of the thing that Lord Yuan of Sung recruitment draftsman, he thought the man who is anxious to paint is not really a painter, only the miraculous person who is undressed with two legs open, sit two knees slightly bent, shaped like a dustpan, in a leisurely scattering state of seeking fame and wealth, has no intention to paint is the really one. That is to say, it is the real art creation only when artistic creation is entering a state of mind which unfolds heart and open arms to forget himself, emotion, benefit and shape, live a simple life, emptiness and stillness, beyond the rules, let things slide. In terms as the creator, the subjective people also seem inexistence, subjective "nature" (heaven) integrate objective "nature" (heaven), which has entered the state of materialization, this is called "heaven joins to heaven". The creative nature is completely consistent with the formed by nature in such situations. Like his emptiness and stillness theory, Chuang tzu's thoughts of materialization as the epistemology of philosophy has its one-sidedness and extremeness, because it excessively exaggerates the relativity between the things, cancels their respective qualitative regularity. However, in the field of aesthetic and literary creation, his thoughts of materialization is a fairly penetrating theory, because in the real advanced aesthetic and literary creation process, the subject must be heterogeneous isomorphism with the object, destruct the boundaries of each other, which is the mind wanders with things, emotion and circumstance blending, meaning and image fusion often said by later generations literary theorist.

"Heaven joins to heaven” as Chuang tzu's argument about the relationship between people and nature, its meaning is to contact the natural law with the nature. Chuang tzu emphasized that the people transform nature in the practice accord with nature by means of the mastery of nature's laws. In A Cook Was Cutting up an Ox, he pointed out the cook who probes the beauties of heaven and earth and comprehends the principles of the myriad things is adapted to heavenly principles, "lead the very thin blade through the great cavitie", finally "He danced in rhythm to The Mulberry Grove; moved in concert with the strains of The Managing Chief” (CHEN, 2007, p. 116). As for the Woodworker Ch'ing Was Carving Wood placed more emphasis on the people by skilled technology, carrying out art creation in accordance with the laws of beauty, finally "heaven joins to heaven”, all who saw it were as amazed as though they were seeing the work of a spiritual being. Therefore, the spirit of "heaven joins to heaven" also embodies in a free creative spirit. The process in which nature's own endless vitality and unlimited richness found and mastered by the people is the process in which the people integrate and supplement reciprocally, perfect jointly. Chuang tzu advocated the beauty of nature in the artistic creation state, "heaven joins to heaven" is the ideal natural artistic state of Chuang tzu. 
The perfect performance of "heaven joins to heaven" is the nature's mystery run automatically. The concept "nature's mystery" is out of Autumn Floods: "How could we change the movements of our natural inner workings" (CHEN, 2007, p. 499) refers to the inartificial vital functions, or the natural sense of life. It is innate without thinking, neither minded choice nor replaced at will. Therefore one thing has its nature's mystery, it is the unique special talent and the most appropriate way of behavior. Such being the case, how to heaven joins to heaven in literature and art creation? Chuang tzu replied "meet with spirit”. The concept of "meeting with spirit" comes from the story of A Cook Was Cutting up an Ox in Essentials for Nurturing Life. That meeting with spirit is to apply people's own mind to understand the essence of things, it is the directly fit and not keeping anything from each other of the heart and things. People don't have to observe and think intentionally after reaching the state of meeting with spirit, simply run the spirit unconsciously, can do anything conform to the inherent laws of things. Meeting with spirit is a psychological state in which the subject and object excellent combination, it is far beyond the operation technology level. The creation of literature and art requires us to enter into things with unconscious natural state of mind, to combine with things, to feel and experience naturally.

\section{The Cognitive State of Lao tzu and Chuang tzu-The Great Semblance Is Invisible}

Taoism adapted to the tradition to group into Tao, Lao tzu had a high regard for stillness and closeness while Chuang tzu praised profound grand and the unrestrained highly, they thought the instant and eternity, a small plot of land and the unlimited space and time as equivalents, in pursuit of chaos in one with Tao. As the result, they took the great semblance is invisible, the great voice is no sound and the great wisdom appears stupid as the highest state of cognition, so as to realize the carefree wandering.

As the aesthetic ideas in Chinese ancient literary theory, the great voice is no sound and the great semblance is invisible were put forward by Lao tzu. They are out of Laozi: "Its largest square doth yet no corner show a vessel great, it is the slowest made; Loud is its sound, but never word it said; A semblance great, the shadow of a shade" (CHEN, 2003, p. 229). These phenomena show the do-nothing state of Tao. It said also: "We listen to it and do not hear it, we name it the Inaudible" (CHEN, 2003, p. 126). Wang Bi noted: "The great voice is the inaudible voice. Where there is voice there is distinction, the distinction is either Gong or Shang. The distinction can't govern the many, so the voice is not great voice" (WANG, 1980, p. 113). "The many" is the whole, "the distinction" is part; the voice such as the Gong or Shang listened by the people are only partially rather than the whole, means that if we have a specific, part beauty of the voice, we will lose the natural beauty of the voice. The great voice is no sound, the do-nothing natural music is the music of Tao, fits the characteristics of Tao, is the ultimate of all artificial music, exists anywhere, includes anything. It is the most beautiful, but silent, is the highest state of music. Although artificial music is wonderful, the beauty of the voiced music is secular and temporary, can make people deaf, it is not suitable to be advocated. Great beauty, extremely beauty-the real beauty is nothing but Tao itself; the real beauty is in nowhere but the existence of Tao. The reason why the real beauty is beautiful is that it accords with the Tao, expresses the Tao and realizes the Tao. The basic feature of Tao is natural, therefore natural is the basic feature of beauty. From the perspective of its second meaning, nature refers to the natural state as the "fact" existence which has not been rationalized that is to say has not been humanization on the ontological significance. The real beauty is out of nature, limited by reality, root in do-nothing. All beautiful things in the world should be natural pure, not be injured by any external powers. The 
form of beauty is varied, but the real beauty is not tend to be restricted to form, pale in the expression. The true meaning of the great voice is no sound and the great semblance is invisible actually emphasizes that the highest beauty is often the most pure, the most natural and the most genuine, and don't need, don't attached to the external phenomenon and form, therefore the beauty which can transcend specific, external, convoluted and artificial beauty is the real "great beauty", "ultimate beauty", on the contrary, it is the "tiny beauty" and "false beauty". "The great voice is no sound and the great semblance is invisible" is the highest state of art and beauty. It reveals that the most perfect literary works must be into the state of Tao, into the natural state which is unaffected simple without any artificial trace.

Discussing the beauty and art, Lao tzu advocated to obey the nature, abandon the man-made things, discard the artificial beauty and art, what he wanted are the literature and art in line with the natural which completely abandon the man-made things, the state of beauty which is in line with the Tao. He thought that the most beautiful voice is the voice that has got rid of artificial rhythm, the most beautiful image the natural image without any man-made cut and polish, The no sound great voice and the invisible great semblance is the natural beauty perceived by the subject self-examination which is either associated with a specific aesthetic feeling or beyond the limited sense of beauty, is the highest state of all art and beauty, people actually have entered into the state of Tao when he reached this state. Chuang tzu's "the great beauty silent" is the same, in Mending Nature he appreciated the ancient people "at that time, there was no action but only constant spontaneity" (CHEN, 2007, p. 468). Here the nature is the meaning of its own, the lively noumenal self of things in the universe, the appearance as it is of things in the universe, beauty of heaven and earth appears in this process. Because the self, just as it is appearance of this beauty, it is a great beauty-“Heaven and earth have great beauty but do not speak” (CHEN, 2007, p. 650). The great beauty of heaven and earth is a kind of beauty united as one without any right or wrong and any difference, is the highest beauty that "its tranquillity would be unlimited, yet a multitude of excellences would follow in its wake" (CHEN, 2007, p. 456), like the high of the sky, the wide of the earth, the running of the sun and the moon, the flourish of the things, they do not speak, therefore "erudition does not necessarily imply knowledge and disputation does not necessarily imply wisdom” (CHEN, 2007, p. 656), Chuang tzu thought that the great beauty is no sound because of itself running, the itself running is Tao. The advocating to natural perfection by Lao tzu and Chuang tzu has profoundly influenced on the later literary theories, it becomes the highest artistic state which is advocating natural without any cut and polish pursued by the writers and artists.

Besides the no sound great voice and the invisible great semblance, the 45 chapter of Laogzi also proposed that "the greatest art still stupid seem". Here Lao tzu analyzed the dialectical relation between skillfulness and unskillfulness relying on the philosophical thought that "nothing can't be done at the point of non-action”. He thought that the real clever is not contrary to the laws of nature to show off its own intelligent but comply with the laws of nature in everywhere, naturally get the purpose of oneself in the process of adaptation. Although the original intention of "The greatest art still remember seem" proposed by Lao tzu did not lie in aesthetics, but explaining the reason of "action through inaction", it has just explained the characteristics of all highly successful art creations. Any outstanding art works is a high degree of unity of purpose and regularity. After Lao tzu proposed that "the greatest art still stupid seem", the dialectical relationship between clever and awkwardness gradually became an important question often discussed by Chinese aesthetics. 
Lao tzu thought that really smart beautiful things should be not modified, so in chapter 81 of Laozi he proposed “sincere words are not fine; fine words are not sincere” (CHEN, 2003, p. 349). The "sincere” refers to the reliable, true. The meaning of this sentence is the content of rhetoric words or articles tend to be untrue. Lao tzu turned up his nose at all kinds of hypocritical superficial and flashy phenomenon in society then. He often told the people not to easily believe the flashy beautiful things, should observe calmly from the dialectics of "the movement of the Tao by contrary proceeds” (CHEN, 2003, p. 226). The thought is of great enlightenment to applying of the methodology on aesthetic judgment and literary criticism.

When Chuang tzu met the Tao at the untrammeled state of mind, what he showed us is a wonderful realm full of very amazing images in Carefree Wandering: Not only the lunker is too large to measure, what is called "in the darkness of the Northern Ocean, there is a fish named Kun. The Kun is so big that no one knows how many thousands of li its body extends. After it metamorphoses into a bird, its name becomes Peng. The Peng is so huge that no one knows how many thousands of li its back stretches. Rousing itself to flight, its wings are like clouds suspended in the sky” (CHEN, 2007, p. 6), but also the tiny is too small as travelling air or floating dust, what is called "the galloping gusts on the open country and motes of dust in the lower sky are blown about by the breath of living organisms" (CHEN, 2007, p. 8) almost can hardly be seen. In this article Chuang tzu showed us three different states: the secular state, the immortal state and the nothingness state.

The secular state is a supposed narrative pattern in the works of Chuang tzu. In the reality level namely the secular state, the people's cognition is based on the assumption, determines the size of different height and length according to their own feeling about time and space and assumptions of the experience, such as the Kun and the Peng are large, the cicada and the turtledove are small. But what is the real world, the real time and space? Its innate quality will never show in front of people without shelter. Therefore, Chuang tzu showed us the immortal state, in his works, the immortals on the mountain MiaoGuye can simply enter into their own inner mind, almost reach the state of no form and no trace. But the immortal state has not yet arrived, although it draws itself from all nature, beyond the human experience and wisdom, beyond the external world to enter into the unconstraint of the heart, it has not walked away from the inner of itself, although the immortals can travel outside the universe, as the subject "I" still makes up the corresponding relationship to each other with the time and space outside the universe, space and me are two different concepts, my lightheartedness has by no means been a whole with the space. If people abandon consciousness of feelings and the wisdom of human being, they can jump out of the real space felled by the people to fade in other state, in this case there is no debate about the size, free themselves from all bondages, beyond the objects relationship around us, as even beyond ego itself to result in selflessness, just get start the open and reveal of another state, which is inexhaustible state, the so called the nothingness state. The excellent spiritual aspect endowed to these sages by Chuang tzu is travelling in the universe, surpassing the things without injury, a state of mind in which the spirit roam in the universe with nothing to fall back on, has the free connotation of aesthetic. In Chuang tzu's view, the function of the spirit lies in the creative travel, and the process of the creation is the process in which spirit releases freely, the two process is the process from one to two, from two to one. Started from the value that the spirit is free and unrestrained, Chuang tzu greatly displayed the imaginative space of literature. But his yearning to the nothingness state makes his cognition more approximate to the Tao. 


\section{The Cognitive Performance of Lao tzu and Chuang tzu-Illocutionary Force}

Although the world is full of linguistic speculation and wisdom, it never reaches the contented perfect state. Facing to the uncertain affairs of human life and the perpetual cycle of all things on earth, Chuang tzu felt that all speech is powerless in front of it, because "speech is not merely the blowing of air. Speech is intended to say something, but what is spoken may not necessarily be valid” (CHEN, 2007, p. 62). Heaven and earth have great beauty but do not speak, the sense of beauty is extremely meticulous and thorough to all nature, which make the people who get it enlightenment through inspiration, it can't be positioned and qualitative indeed, but has to through the speech of language can it convey to others or future generations. Just like German philosopher heidegger's saying "in the narration, a nation historical understand their world, but the earth keeps still closed. The projective speech is such a speech, it has prepared the speakable, bring the unspeakable into the world at the same time” (Heidegger, 1990, p. 69). Because the language is limited, fixed, specific alleged, but Tao is infinite, sportive, comprehensive, contradiction inevitably forms between them. There are two different levels in the speech as language, one can be expressed by words, but the other can't be expressed by words, namely the unspeakable. Speech undoubtedly has its limitations, just like Heidegger saying, when we think about it, we experience in existence itself. Although the individual can experience and understand the state of great Tao when he(she) faces to the world and the nature, no language can describe it, however, the speech as narration is indispensable when it is conveyed to others. So we have to face the paradox of life, speak the unspeakable.

Tao is the opposite time and condition which is unspeakable and can't be bound in mind, it is distant and unreal, erratic and traceless, is nothing but naturally tacit identity. When we ask, speak and try to understand the Tao, perhaps it is opened, or appears in some moment, but the appearance isn't itself, so Lao tzu said: “The Tao that can be trodden is not the enduring and unchanging Tao. The name that can be named is not the enduring and unchanging name” (CHEN, 2003, p. 1). In The Way of Heaven and Autumn Floods, Chuang tzu thought, there is prodigious a difference between the language and the intention when people as cognitive subject realize and grasp the abstruse Tao, although the intention can't completely observe the lofty Tao, can grasp some subtleties in the final analysis, namely its minuteness. However, the word and book record word at best only grasp its coarseness, therefore even if the articles and works (books) are only waste matter, should be disdained. His seemingly extreme absurd viewpoint actually contains very incisive reasonable kernel, that is to say the people's words and books (including literature works) are not competent when they express complicated intentions, they are nothing but lame tools, this is the original source of the famous viewpoint of "the word fails to convey the meaning” in the later literary theory history.

Just because the word fails to convey the meaning, Chuang tzu put forward the so-called point of "gain its meaning but forget the words”. He wrote in External Things:

A fish-trap is for catching fish; once you've caught the fish, you can forget about the trap. A rabbit-snare is for catching rabbits; once you've caught the rabbit, you can forget about the snare. Words are for catching ideas; once you've caught the idea, you can forget about the words. (CHEN, 2007, pp. 832-833)

In Chuang tzu's viewpoint, words doesn't convey all its connotation, means the word fails to convey the meaning. He said: "Meaning is what gives value to words, but meaning is dependent on something. What meaning depends on cannot be expressed in language” (CHEN, 2007, p. 413). Chuang tzu emphasized the 
limitation of language and word, pointed out that it cannot fully express the complicated content of human being thought. This view to a certain extent accords with the actual situation of people's cognitive practice, but also has its obvious limitations. Chuang tzu's viewpoint of "gain its meaning but forget the words" based on "the word fails to convey the meaning" stressed the purpose of words is to gain its meaning, means to express ideas, therefore should not be constrained the words as tool and cling to it so as to forget the purpose of gain its meaning. On the contrary, as long as the meaning is clear, things can make people understand, it does not matter to forget the words. The viewpoint of "gain its meaning but forget the words" profoundly affected the literary creation. Literary works require implication and aftertaste, often ask to blanket more with less, pursue "taste the implied", "illocutionary force", Chuang tzu's viewpoint of "gain its meaning but forget the words" just tell us the mystery of the relations between words and meaning in literary creation.

Although intangible and traceless, the Tao is ever changing as well, deposits in existence. The mission of the language is to convey feeling and ideas, the language can be abandoned after the conveying, therefore Chuang tzu said: "That which can be discussed in words is the coarseness of things; that which can be conceived of in thought is the minuteness of things" (CHEN, 2007, p. 485). The fine meaning cannot be expressed by language, what can be expressed is the phenomenon of things and general reason, but the essence of things, the beauty of the object lie in the unspeakable implied meaning. Because we speak the unspeakable Tao, we must borrow another alternative way, the so-called fasting, by the existent object, evolve into aesthetic observation, show the illocutionary force, only in this way can we get rid of external obstructions such as the wisdom of language to get the truth of great Tao. Study from given above, the so-called the implied meaning is the intuitive grasp in fact. Since Chuang tzu proposed the difference between the language communication and the obtaining the meaning, the implied aim in the article, the overtones, the illocutionary force, the meaning outside language have always discussed in the poem criticism, it has developed a centuries-old tradition in Chinese literary theory history.

\section{Conclusion}

Different from the cognitive poetics established by Western scholars based on the language and words of text after all kinds of subject came into being, Lao tzu and Chuang tzu through the intuitive experience to understand and experience the things, started from the relations of the heaven, the earth and human beings, set up their own cognitive aesthetics system in the early years of human. They required the subject of literary and artistic creation to surpass the reality, obtain spiritual freedom, fasting, sit and forget, forget himself and other things, keep the mind clear and bright, grasp the innate character of nature. The perfect cognitive state of literary and artistic creation is that the great semblance is invisible, the great voice is no sound, the great wisdom appears stupid.

\section{References}

CHEN, G. Y. (2003). Modern note and translation of Laozi. Beijing: The Commercial Press. CHEN, G. Y. (2007). Modern note and translation of Zhuangzi (Vol. 1). Beijing: The commercial Press. CHEN, S. G. (2006). Proofreading and notes to the Four Books and Five Classics. Changsha: Yuelu Press. Heidegger, M. (1990). Poetry, language, thoughts. Beijing: Culture and Art Press. WANG, B. (1980). Proofreading and notes to the corpus of Wang Bi. Beijing: Zhonghua Book Company. 